\title{
Finite element modelling of microstructural changes during equal channel angular drawing of pure aluminium
}

\author{
Serafino Caruso $^{1}$ (D) $\cdot$ Stano Imbrogno ${ }^{2}$ (D) \\ Received: 14 January 2021 / Accepted: 18 March 2021 / Published online: 29 March 2021 \\ (C) The Author(s) 2021
}

\begin{abstract}
Grain refinement by severe plastic deformation (SPD) techniques, as a mechanism to control microstructure (recrystallization, grain size changes,...) and mechanical properties (yield strength, ultimate tensile strength, strain, hardness variation...) of pure aluminium conductor wires, is a topic of great interest for both academic and industrial research activities. This paper presents an innovative finite element (FE) model able to describe the microstructural evolution and the continuous dynamic recrystallization (CDRX) that occur during equal channel angular drawing (ECAD) of commercial 1370 pure aluminium (99.7\% Al). A user subroutine has been developed based on the continuum mechanical model and the Hall-Petch (H-P) equations to predict grain size variation and hardness change. The model is validated by comparison with the experimental results and a predictive analysis is conducted varying the channel die angles. The study provides an accurate prediction of both the thermo-mechanical and the microstructural phenomena that occur during the process characterized by large plastic deformation.
\end{abstract}

Keywords Microstructural changes · Dynamic recrystallization · Grain size $\cdot$ Aluminium $\cdot$ Finite element modelling $\cdot$ Equal channel angular drawing

\section{Introduction}

Commercially pure aluminium wire has attracted the interest of automotive industry due to the light weight (a third of steel), corrosion resistance (it naturally generates a protective thin oxide coating), good electrical conductivity, ductility (products near to net shape), and higher mechanical strength to weight ratio. Indeed, aluminium and its alloys are used in vehicles to reduce the dead-weight, energy and fuel consumption while increasing load capacity $[1,2]$.

Since functional performance and service safety are two aspects of great rank for automotive industry, an accurate knowledge of the microstructural evolution (i.e. grain refinement) that occurs during wire production is required. Indeed,

Serafino Caruso

serafino.caruso@unical.it

1 Department of Mechanical, Energy and Management Engineering, University of Calabria, 87036 Rende, CS, Italy

2 School of Metallurgy and Materials, University of Birmingham, B15 2TT, Birmingham, UK the microstructure is strictly related to the strengthening mechanisms of the material.

In this contest, the grain size and recrystallization are fundamental aspects that need to be controlled for an efficient production development [3-5]. Severe plastic deformation (SPD) processes, in which a high shear strain is imposed on the material, are recognized as the main techniques to achieve microstructural changes by the recrystallization [6-8].

Many SPD methods were developed during the past three decades [9], but the concept of Equal Channel Angular Drawing (ECAD) [10] represents the most successful SPD technique for continuous production of ultra-fine-grained materials with homogeneous equiaxial microstructure.

In ECAD process, the specimen is drawn through a die consisting of two channels of equal cross section intersecting at an angle $(2 \phi)$, usually between $90^{\circ}$ and $135^{\circ}$, preserving its transversal dimension (Fig. 1).

Previous works have already investigated and analysed microstructural evolution, SPD and ECAD process of pure aluminium samples.

Pérez et al. [11] investigated the effect of two different processing ways and heat treatments during ECAD process of 1370 aluminium alloy with five passes at room temperature. In 


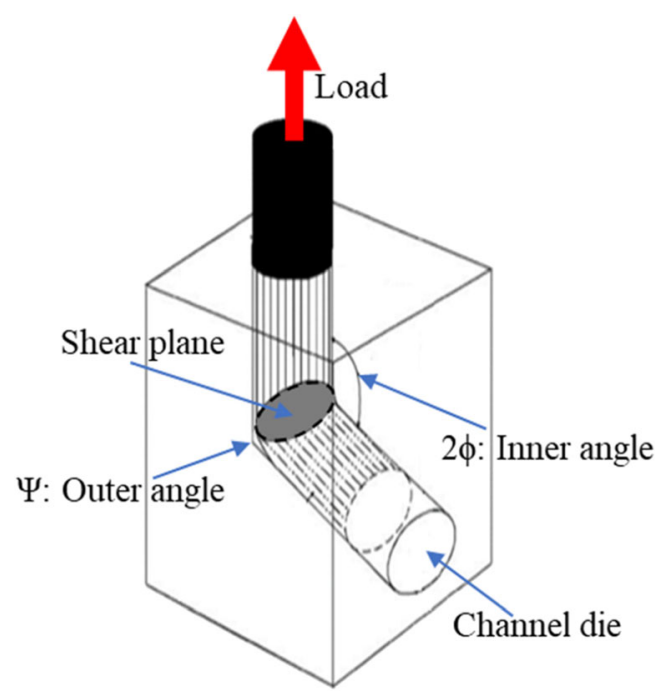

Fig. 1 Schematic illustration of the ECAD process

particular, the authors processed the workpiece through two different routes: route A (no rotation of the workpiece between the steps) and route $\mathrm{B}\left(\mathrm{a} 90^{\circ}\right.$ rotation of the workpiece at each step). Moreover, two different die channels were implemented for each route. The experimental results confirmed that, compared to the initial condition, a grain refinement occurred leading to recommend the ECAD method as an intermediate process during aluminium alloys wire drawing.

Chakkingal et al. [12] investigated the mechanical properties and microstructural evolution of pure aluminium 3004 when processed by 6 passes of ECAD method consisted of two square channels of cross-sectional area $15 \times 15 \mathrm{~mm}^{2}$ intersecting at an angle of $135^{\circ}$. The experimental results showed an increase of the tensile strength, the yield strength, hardness, and a grain refinement from 2000 to $1 \mu \mathrm{m}$.

Hou et al. [13] analysed the commercially pure aluminium wires (CPAWs) by tensile tests, electron backscatter diffraction (EBSD) and transmission electron microscopy (TEM) observations to establish the relation between the mechanical properties and the microstructural evolution. The outcomes showed as the texture, grain size and dislocation density mainly influence the performance of the material after the drawing process.

Zisman et al. [14] investigated the mechanical properties, the textures and microstructures of the sheet metals processed by a new simple method of ECAD, with adjustable die opening, comparing the obtained results with closely related process technique.

Zhu et al. [15] examined the effect of the stress profile on the texture evolution of the CPAW by combining the numerical results with the microstructural observations. A FE model was developed to better understand the relationship between the stress profile and the microstructural evolution during the multi-pass cold drawing of the CPAW. The results showed the plastic deformation mode on the wire cross section, the stress contribution to the texture formation and the average grain size evolution from the wire surface to its centre.
Chakkingal et al. [16] presented a study of three different routes of the ECAD process on pure commercial aluminium bars with extremely coarse grains (of the order of $2000 \mu \mathrm{m}$ in size). The outcomes showed a significant increase in tensile and yield strengths, with a corresponding decrease in ductility. Moreover, micro-sized sub-grains with a shape varying from elongated to equiaxed were obtained. The authors highlighted the usefulness of ECAD process as a continuous industrial method to produce grain-refined bars with increased strength from coarse-grained aluminium.

All these studies suggest the important role of the microstructural evolution in enhancing the mechanical properties of the aluminium alloys as well as the suitability of the ECAD processes for refining the grain structure. Therefore, it is also useful to develop an adequate FE numerical model to predict and control the thermo-mechanical phenomena that occur during the investigated processes since they are fundamental for the mechanical performances and the quality of the final product.

In this paper, an advanced flow stress empirical model that includes the grain size variation was developed to predict the material behaviour of commercial 1370 pure aluminium wires (Al 99.7\%) during ECAD process. Once defined all the constants of the material flow stress model, a continuum mechanical model and H-P equation were implemented by two customized user sub-routines. Therefore, the developed model was able to predict the grain refinement and hardness variation during the investigated process. Finally, a comparison between numerical results and the corresponding experimental data was carried out to validate the developed model and to show the effectiveness of the proposed numerical tool.

\section{Experimental procedure}

Commercial 1370 pure aluminium rods (Table 1) with an initial diameter of $9.50 \mathrm{~mm}$ were analysed. A multiple-pass cold drawing was performed at room temperature to produce wires with final diameter of $2.00 \mathrm{~mm}$ after 15 passes, with a total section reduction of $95.6 \%$ and a total drawing strain of 3.11 (Fig. 2).

ECAD process, with an inner die angle $\Phi=140^{\circ}$ and outer die angle $\psi=\pi-\Phi$, as shown in Fig. 3, was performed at room temperature on the cold-drawn wires preserving their transversal dimensions, with a drawing speed of $25 \mathrm{~m} / \mathrm{s}$.

Uniaxial tensile tests of the aluminium rods, drawn wires and ECAD processed wires were carried out using the MTS

Table 1 Material chemical composition

\begin{tabular}{lllllllllll}
\hline $\mathrm{Al}$ & $\mathrm{Si}$ & $\mathrm{Fe}$ & $\mathrm{Cu}$ & $\mathrm{Mn}$ & $\mathrm{Mg}$ & $\mathrm{Cr}$ & $\mathrm{Ni}$ & $\mathrm{Zn}$ & $\mathrm{B}$ & $\mathrm{Ga}$ \\
\hline 99.7 & 0.10 & 0.25 & 0.02 & 0.01 & 0.02 & 0.01 & - & 0.04 & 0.02 & 0.03 \\
\hline
\end{tabular}



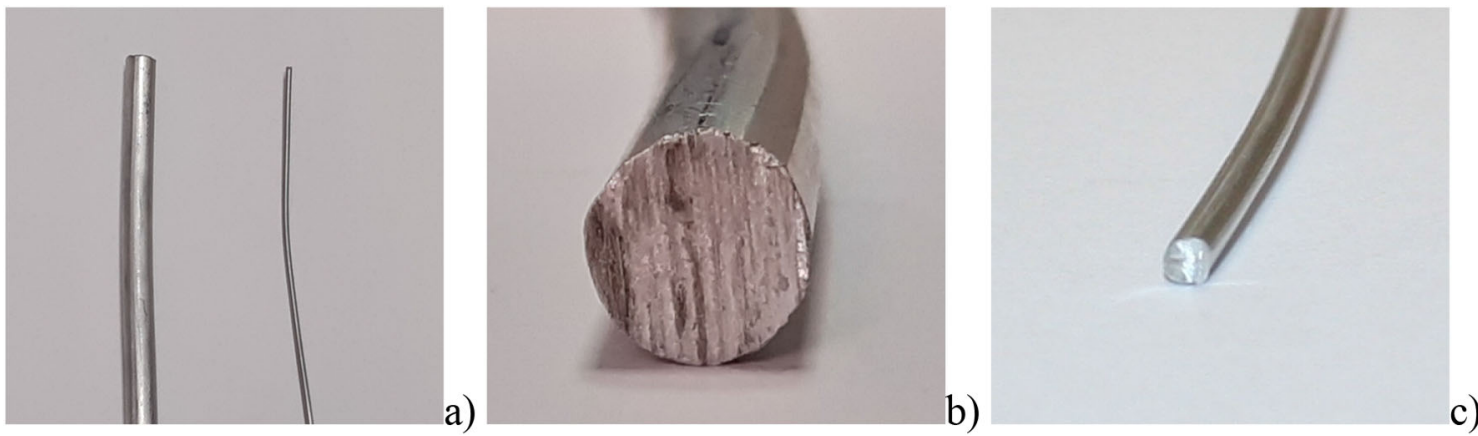

Fig. 2 a Analysed samples. b Initial aluminium $\operatorname{rod} \phi=9.50 \mathrm{~mm}$. c Cold-drawn wire $\phi=2.00 \mathrm{~mm}$

Criterion Model 45 testing machine and all the tests were performed at room temperature. In particular, nine samples (three aluminium rods, three drawn-wires and three ECAD processed wires) were analysed and the average value of the stress-strain profile measured for the three type of samples is reported in Fig. 4.

The tensile tests show as the material strength was enhanced when both drawing and ECAD process are performed on the aluminium wire. In detail, the value of the yield strength and the ultimate tensile strength were higher while the ductility decreased, indeed the true strain $(\varepsilon)$ dropped from 0.11 to 0.08 after cold-drawing. This result agrees with Luo et al.'s [17] outcomes. Indeed, they demonstrated an increase of the yield strength and a decrease of the elongation when drawing pure aluminium wire from an initial diameter of 9.5 to $2.99 \mathrm{~mm}$ after 9 passes. Moreover, a further enhancement of $30 \mathrm{MPa}$ in material strength was observed after ECAD process on drawn wires with a reduction of the true strain of 0.04 . The plastic deformation of each drawing pass and the SPD imposed by ECAD die led to an increase of the material strength due to the hardening effect produced by the accumulation of the dislocations $[13,18]$ and the Hall-Petch $(\mathrm{H}-$ P) effect induced by the microstructural phenomena (i.e. grain refinement).
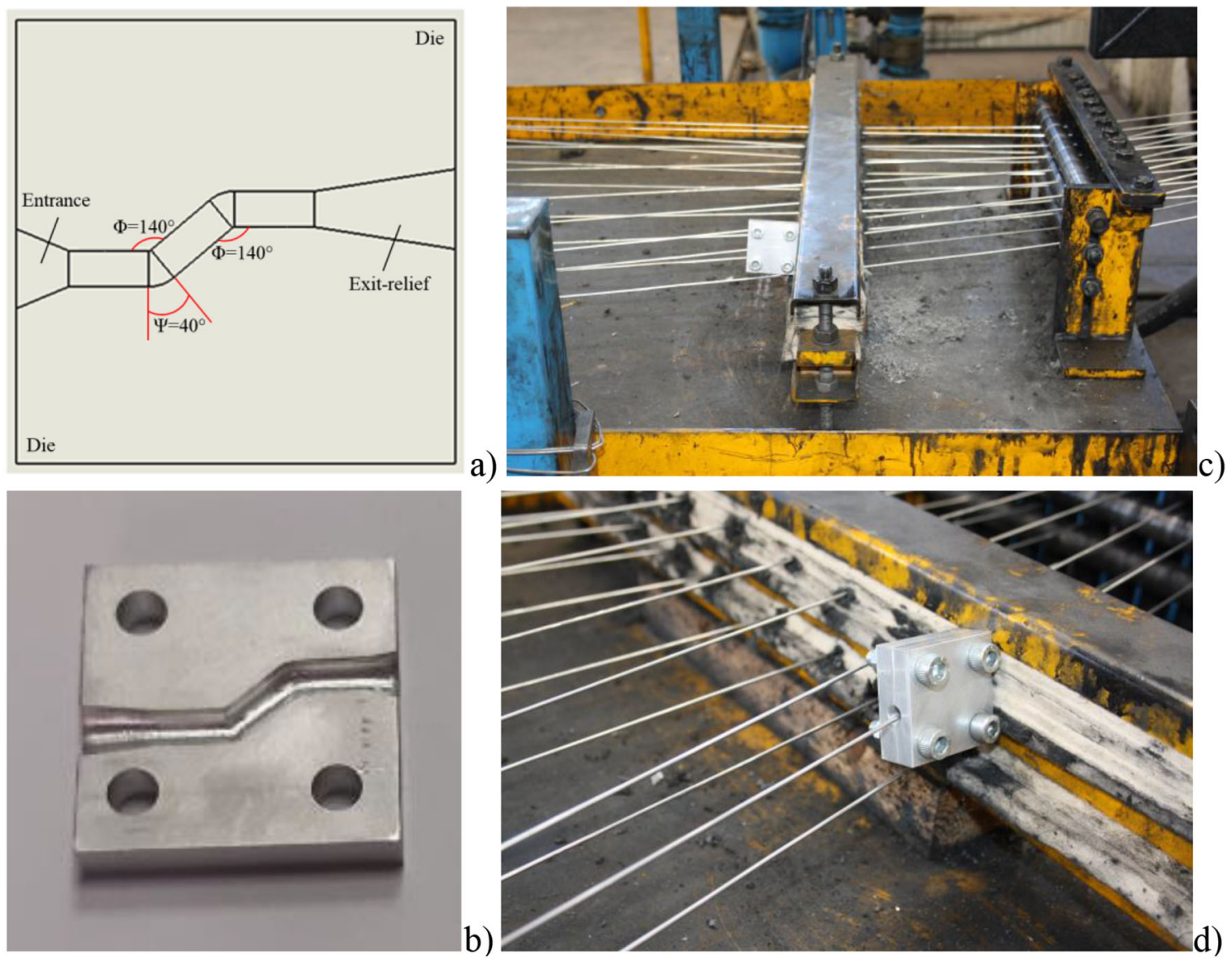

Fig. 3 a, b Geometry of the ECAD die. c, d Experimental set-up 


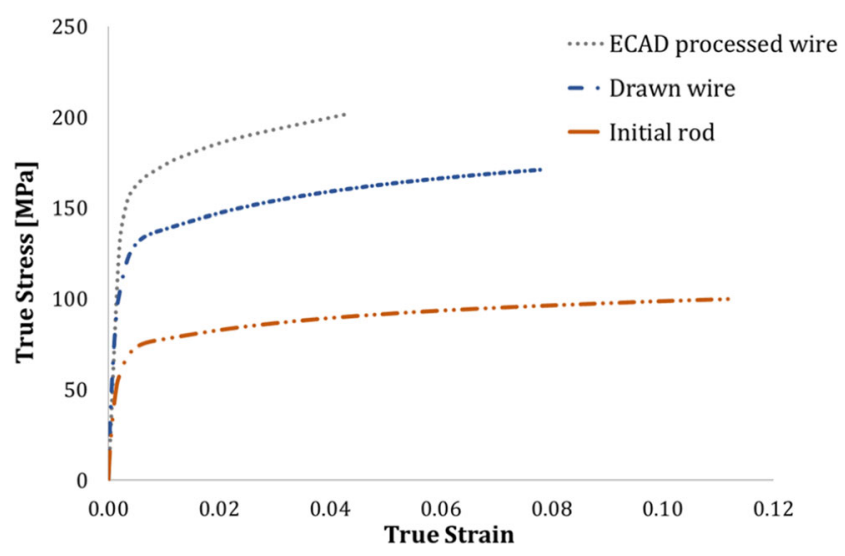

Fig. 4 True stress-strain curve

Subsequently, samples of initial aluminium rods, colddrawn wires, and ECAD processed wires were cut and the transverse section was mounted into a resin holder for the microstructural analysis.

The metallographic preparation consisted of mechanical polishing and then etching by the use of Keller's reagent ( $92 \mathrm{ml}$ of distilled water, $6 \mathrm{ml}$ of nitric acid, $2 \mathrm{ml}$ of hydrochloric acid, $2 \mathrm{ml}$ hydrofluoric acid). The cross section of the three samples was analysed using an optical microscope for microstructural analysis, while the micro-hardness $\left(\mathrm{HV}_{0.01}\right)$ was investigated by an instrumented micro-nano indenter.

Figure 5 reports the micrographs obtained by the optical microscopy analysis. In Fig. 5a, the grains are analysed under polarized light to better show the grain morphology. It is possible to observe that the grains, although the elliptical shape, mostly look equiaxial and the average measured diameter was equal to $58 \mu \mathrm{m}$. Figure $5 \mathrm{~b}$ and $\mathrm{c}$ report the grains structure after the cold-drawn and the ECAD respectively. It is clear the effect of the drawing process on the grain refinement. In Fig. 5b, the grains still maintain their morphology (grain boundaries represented by the black and thicker lines) although the size is significantly reduced and the average value was equal to $11 \mu \mathrm{m}$. Finally, in Fig. $5 \mathrm{c}$, the micrograph shows the cross section of the ECAD sample. It appears also in this case the grain refinement induced by the ECAD and a change in the grain morphology (grains shape more equiaxial than elliptical). For this latter sample, the average measured grain size was equal to $6 \mu \mathrm{m}$. Considering the initial grain size of the aluminium rods $(58 \mu \mathrm{m})$, the total processes' deformations allowed to reach an overall reduction of $81 \%$ (Fig. 5).

The micro-hardness was measured on nine samples (three aluminium rods, three drawn-wires and three ECAD processed wires), and ten indentations per sample were carried out for a total of 90 tests and the average value was considered (Fig. 6). A significant increase of $14 \mathrm{HV}$ was first observed at the end of the 15 drawing passes and $9 \mathrm{HV}$ more after ECAD process for a total hardness increase of 59\%. In both cases, the hardness variation is mainly due to the evolution of the microstructure, during the large strain, which results in grain refinement due to the dynamic recrystallization (DRX) phenomena as well as work hardening.

\section{Numerical model}

The commercial FE software SFTC DEFORM-3D ${ }^{\mathrm{TM}}$ has been used to simulate the ECAD process of commercial 1370 pure aluminium drawn-wire using coupled thermomechanical analysis with automatic remeshing. The workpiece was modelled as a plastic body meshed with 50000 isoparametric tetrahedral elements, while for the die a rigid model with 64,000 elements was considered (Fig. 7).

To simulate the material behaviour under SPD condition, a modified Johnson-Cook (J-C) flow stress model was developed. According to the original J-C model, the flow stress is expressed as Eq. 1.

$\sigma(\varepsilon, \dot{\varepsilon}, T)=\left(A+B \varepsilon^{n}\right)\left(1+\operatorname{Cln}\left(\frac{\dot{\varepsilon}}{\dot{\varepsilon}_{0}}\right)\right)\left(1-\left(\frac{T-T_{0}}{T_{m}-T_{0}}\right)^{m}\right)$

where $A$ is the yield stress at reference temperature and strain rate, $B$ and $n$ are respectively the coefficient and the exponent of strain hardening, $C$ is the coefficient of strain rate hardening, $\varepsilon$ is the equivalent plastic strain and $\dot{\varepsilon}$ and $\dot{\varepsilon}_{0}$ are the plastic strain rate and the reference plastic strain rate respectively. $T_{0}$ is the reference temperature, $T_{m}$ is the melting temperature and $m$ the thermal softening exponent.
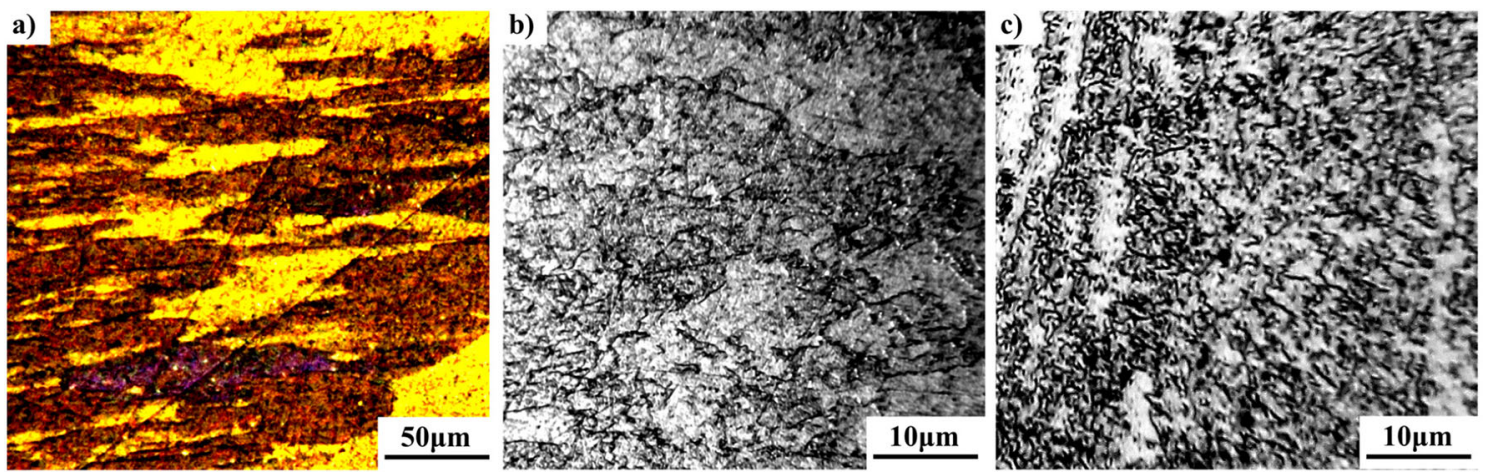

Fig. 5 Transverse section microstructure. a Initial aluminium rod (polarized light). b Cold-drawn wire (bright field). $\mathbf{c}$ ECAD processed wire (bright field) 

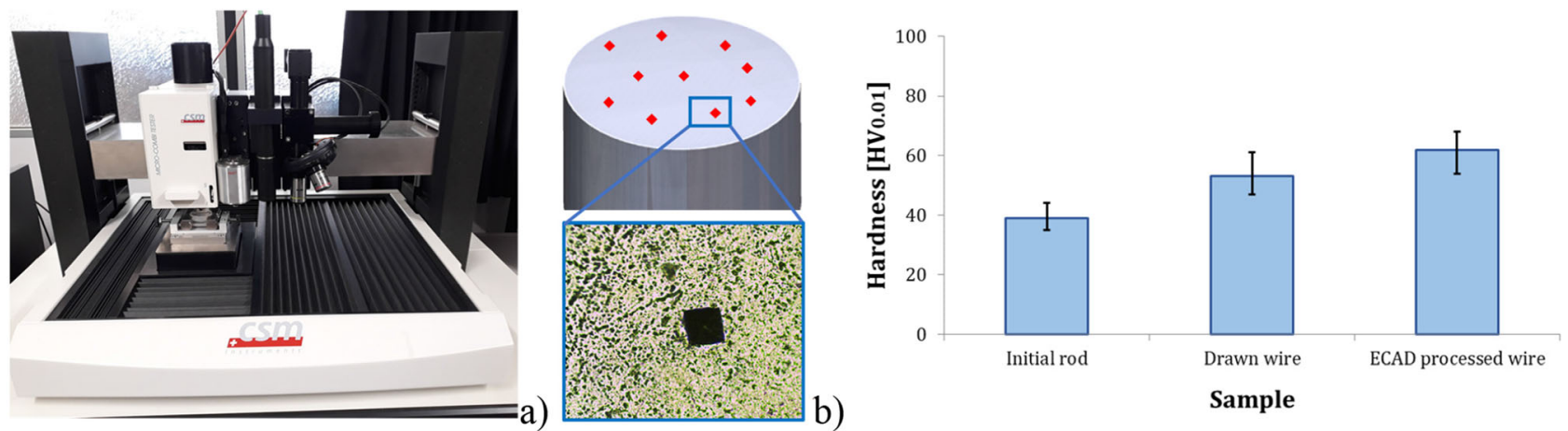

Fig. 6 Transverse section hardness. a Micro-nano indenter. b Transverse section indentation analysis. c Measurements

The model proposed in this research modified the constant $A$ (MPa) of the flow stress in Eq. 1 to consider the influence of the grain refinement caused by DRX according to H-P equation (Eq. 2).

$A=\sigma_{y}=\sigma_{0}+\frac{k_{y}}{\sqrt{d}}$

where $\sigma_{y}$ is the yield strength, $k_{y}$ is the strengthening coefficient, $\sigma_{0}$ is a material constant and $d$ is the average grain size.

By this modification, the material flow stress is influenced by the DRX that significantly modifies the microstructure of the material resulting in the material strengthening described by the Hall-Petch (H-P) effect.

Thus, the thermo-mechanical behaviour of the pure aluminium is numerically represented by the new modified $\mathrm{J}-\mathrm{C}$ law (Eq. 3).

$\sigma(\varepsilon, \dot{\varepsilon}, T, d)=\left(\left(\sigma_{0}+\frac{k_{y}}{\sqrt{d}}\right)+B \varepsilon^{n}\right)\left(1+\operatorname{Cln}\left(\frac{\dot{\varepsilon}}{\dot{\varepsilon_{0}}}\right)\right)\left(1-\left(\frac{T-T_{0}}{T_{m}-T_{0}}\right)^{m}\right)$

A regression approach was implemented to determine the values of the numerical constants $B, n, C$ and $m$, performing uniaxial tensile tests of the aluminium rods with three different speeds and temperatures (Table 2). Moreover, for each tensile test condition, three tests were considered in order to assess the statistical reliability for a total of 27 experiments and finally the average value was measured.
The numerical constants $\sigma_{0}$ and $k_{y}$ were determined by Eq. 2 through the previously measured values of the yield strength and the grain size of both initial aluminium rods and drawn wires.

All the coefficients of the material behaviour model are listed in Table 3.

The physical events that affect the mechanical properties were predicted by implementing a customized user subroutine with a CDRX model for the grain refinement $[3,18,19]$ and the H-P equation to predict the hardness evolution.

In particular, the CDRX represents the main physics metallurgical phenomenon due to the nature of the material used (pure aluminium) [20-22]; therefore, a continuum mechanical model to predict the grain size was implemented (Eq. 4).

$d=d_{0}-\left(d_{0}-d_{f}\right)\left(1-\exp \left(-k_{x}<\varepsilon^{p} e_{e f f}-\varepsilon^{p}{ }_{c}{ }^{C_{x}}\right)\right) d_{f} \leq d \leq d_{0}$

where $d$ is the recrystallized grain size, $d_{0}$ the initial grain size, $d_{f}$ the saturation grain size and $k_{X}$ and $c_{X}$ are parameters describing the recrystallization evolution with increasing plastic deformation. The McCauley brackets $<>$ indicate that recrystallization phenomena will occur when the effective strain $\varepsilon^{p}$ eff will reach the threshold value $\varepsilon^{p}{ }_{c}$. The model developed by Iwahashi et al. [23] was considered for the ECAD process strain $\varepsilon^{\mathrm{p}}$ eff (Eq. 5).

$\varepsilon_{e f f}^{p}=\left(\frac{N_{p a s s}}{3^{0.5}}\right)\left(2 \cot \left(\frac{\Phi}{2}+\frac{\psi}{2}\right)+\psi \operatorname{cosec}\left(\frac{\Phi}{2}+\frac{\psi}{2}\right)\right)$

Fig. 7 a FE model. b Wires discretization

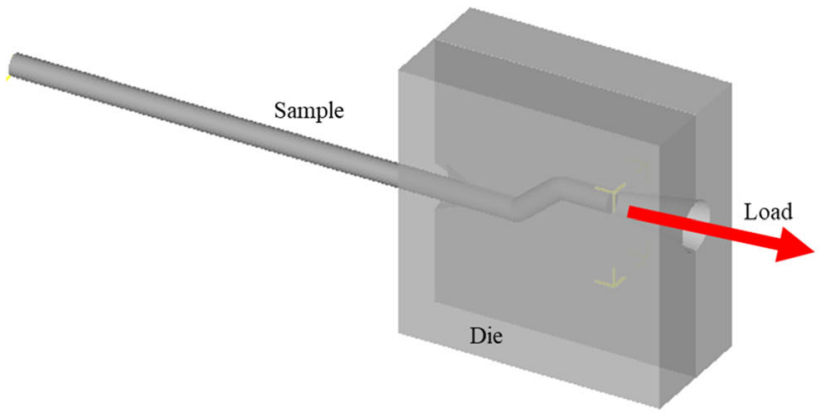

a)

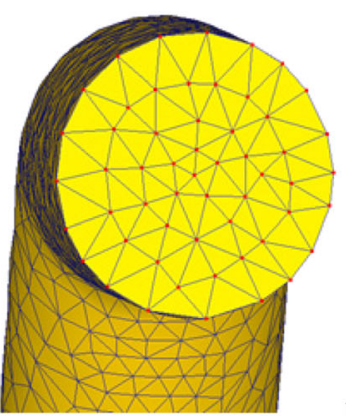

b) 
Table 2 Tensile test conditions

Table 3 Numerical material model parameters

\begin{tabular}{llllll}
\hline$B$ & $n$ & $C$ & $m$ & $\sigma_{0}$ & $k_{y}$ \\
\hline 104.2 & 0.385 & 0.0097 & 1.175 & 16.39 & 370.14 \\
\hline
\end{tabular}

where $\Phi$ and $\psi$ are the ECAD die angles (Fig. 3) and $N_{\text {pass }}$ is the number of ECAD passes.

The parameters $k_{X}$ and $c_{X}$ and the critical strain leading to CDRX were set 3.8, 2 and 0.1 according to [20] respectively.

Finally, the hardness modification depending on the recrystallized grain size was calculated according to the H-P equation that considers hardness evolution as an inverse function of grain size (Eq. 6):

$H V=C_{0}+\frac{C_{1}}{\sqrt{d}}$

where $C_{0}$ and $C_{1}$ are two material constants while $d$ represents the average grain size. The values of $C_{0}$ and $C_{1}$ were determined through the previously measured values of the material hardness and grain size of both initial aluminium rods and drawn wires and were equal to 28.2 and 82.2 , respectively.

\section{$4 \mathrm{FE}$ validation and results}

The FE model was validated by comparing the experimental results of hardness variation and the grain size evolution with the corresponding numerical data.

Figure 8 reports the stable and uniform data prediction of grain refinement and hardness variation and it is possible to observe the effectiveness of the customized model and the user subroutines to successfully predict the phenomena that occur during the ECAD process. In particular, the CDRX takes place since the SPD induced by the die geometry allows the effective strain $\varepsilon^{p}$ eff to overcome the threshold value $\varepsilon^{p}{ }_{c}$. Therefore, a new grain size is calculated and the microstructural changes affect the material behaviour according to Eq. 3 .

The predicted grain size evolution and the hardness variation were measured along five different cross sections of the ECAD processed wire.

According to the experimental outcomes the numerical results show that after the ECAD die, the internal evolution of the microstructural features results in an average grain size that decreases becoming the half size of the as cold-drawn. Thus, according to the inverse function of H-P equation (Eq. 6), the hardness increases confirming that the ECAD process causes severe microstructural and mechanical properties changes (Fig. 9).

Figure 9 shows the comparison between the numerical results and the corresponding experimental data. The comparison analysis highlighted a small difference of $1.2 \mu \mathrm{m}$ regarding grain size evolution and a relative error of $8 \%$ when the hardness changes is predicted. This slight differences between the numerical and the experimental data suggest that the developed numerical procedure is enough robust. The reason of the small difference between numerical and experimental results could be related to both the accuracy of the experimental data and the calibration procedure used to define all the numerical constants of the equations implemented in the user subroutine.

After the validation of the numerical model, a predictive analysis was carried out with the aim to analyse the evolution of the grain size and hardness change when the $\Phi$ die angle is modified. In particular, different simulations were carried out increasing the inner die angle $\Phi$ to $165^{\circ}$ and $175^{\circ}$ with a

Fig. 8 Numerical prediction of a grain size $(\mu \mathrm{m})$ and $\mathbf{b}$ hardness $\left(\mathrm{HV}_{0.01}\right)$
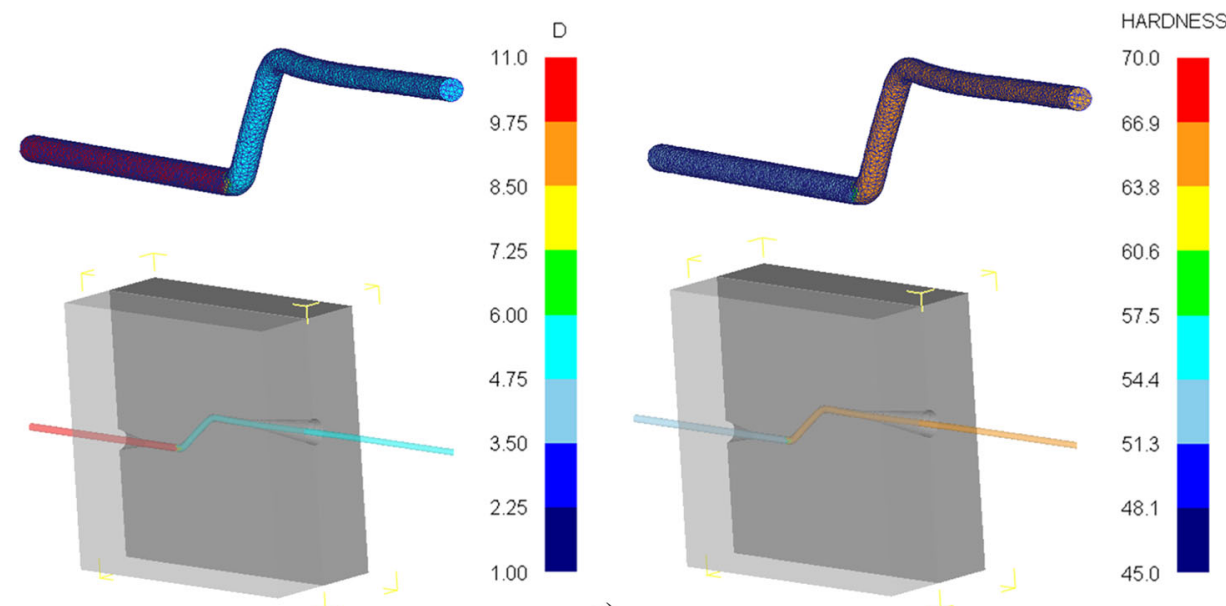

a) 
Fig. 9 Comparison between measured and predicted grain size and hardness variation
ECAD effect

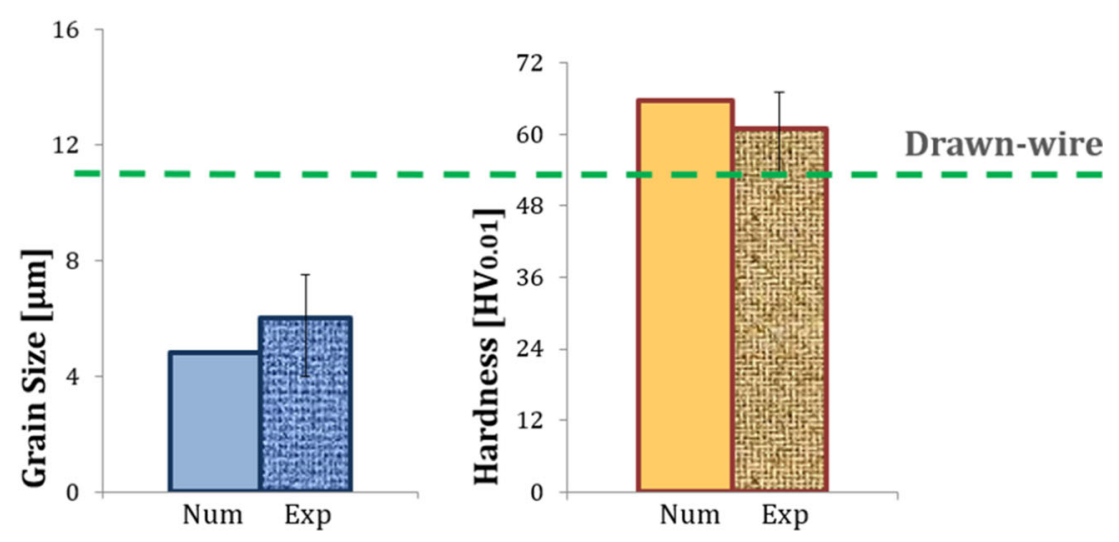

Table 4 Predictive analysis results

\begin{tabular}{lllllll}
\hline$\Phi\left[^{\circ}\right]$ & $\mathrm{d}_{0}[\mu \mathrm{m}]$ & $\mathrm{d}_{\mathrm{f}}[\mu \mathrm{m}]$ & Reduction [\%] & $\mathrm{HV}_{\text {initial }}$ & $\mathrm{HV}_{\text {final }}$ & Rise $[\%]$ \\
\hline 140 & 11 & 4.8 & 56 & 53 & 65.7 & 24 \\
165 & 11 & 10.3 & 6 & 53 & 53.8 & 2 \\
175 & 11 & 11.0 & 0 & 53 & 53 & 0 \\
\hline
\end{tabular}

corresponding outer die angle $\psi=\pi-\Phi$ (Figs. 10 and 11). The numerical results are listed in Table 4.

The predictive analysis highlights as the effectiveness of the investigated ECAD process is related to a limited range of $\Phi$ die angle, between $140^{\circ}$ and $165^{\circ}$ because the channel geometry leads a heavy deviation that results in SPD. Thus, the plastic deformation affects the microstructure of the aluminium triggering the grain refinement process. While high values of the $\Phi$ die angle results in low plastic strain, hence the strengthening effect due to the grain size evolution decreases. Considering the application of the ECAD as a continuous industrial processing step, these results are significantly important since they suggest the impact of the microstructural changes effects and the mechanical properties of the final product as a function of the process parameters and channel die geometry.

\section{Discussion and conclusions}

In this research article, an advanced empirical model, including grain size evolution, was developed to describe the material behaviour of commercial 1370 pure aluminium wires ( $\mathrm{Al}$ 99.7\%) during ECAD process.

A continuum mechanical model and the H-P effect were implemented for predicting the grain size and the hardness evolutions. A new modified J-C model was implemented considering the effect of grain size on the material behaviour during the SPD process. By this modification, the material flow stress is influenced by the CDRX that significantly modifies the microstructure of the material (i.e. grain refinement) resulting in material strengthening for the H-P effect.

The numerical results were validated by comparison with those experimentally found demonstrating the effectiveness of the customized model and the user subroutines to successfully
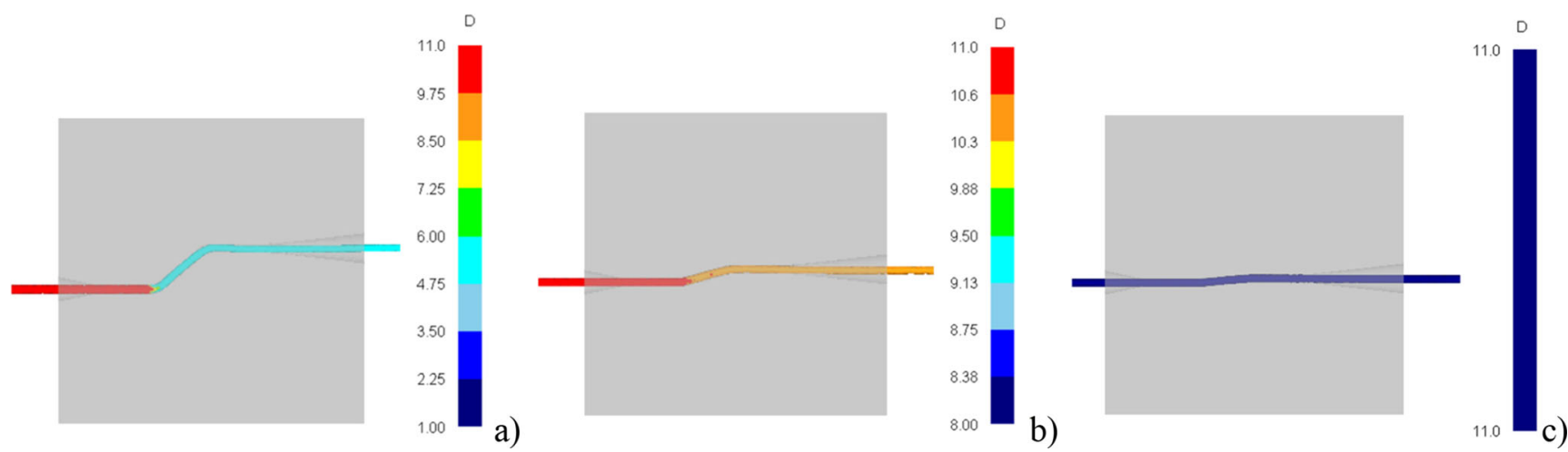

Fig. 10 Grain size predictive numerical analysis. a $\Phi=140^{\circ}$. b $\Phi=165^{\circ}$. c $\Phi=175^{\circ}$ 


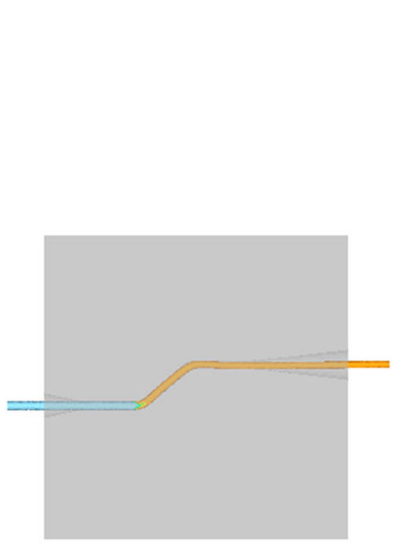

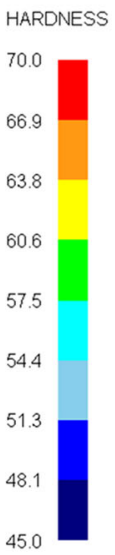

a)

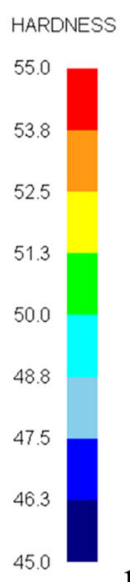

b)

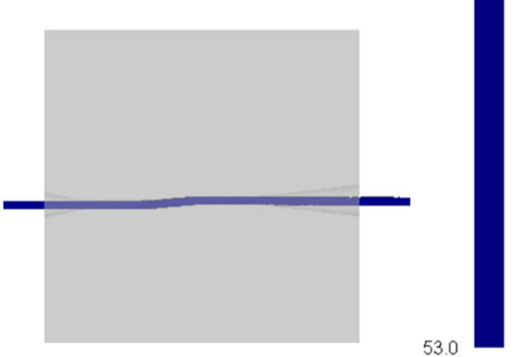

HARDNESS

53.0

c)

Fig. 11 Hardness predictive numerical analysis. a $\Phi=140^{\circ}$. b $\Phi=165^{\circ}$. c $\Phi=175^{\circ}$

predict the CDRX phenomenon, taking place during the ECAD process, due to the high strains induced by SPD.

Finally, a predictive numerical analysis showed the main importance of the die channel geometry in controlling the microstructural changes of the material as well as the mechanical behaviour and the hardening effect.

Thus, the proposed FE strategy can be used to properly simulate the material behaviour of commercial 1370 pure aluminium wires ( $\mathrm{Al}$ 99.7\%) during ECAD process. The model allows to take into account the microstructural characteristics of the material that affect the material flow stress and the hardness. The developed numerical tool can be potentially employed during the design step of the drawing process to accurately achieve the desired mechanical performances required by the product.

Nomenclature $A$, Yield stress; $B$, Numerical constant; $C$, Numerical constant; $C_{0}$, Numerical constant; $C_{1}$, Numerical constant; $C_{X}$, Numerical constant; CPAW, Commercially pure aluminium wire; ECAD, Equal channel angular drawing; CDRX, Continuous dynamic recrystallization; DRX, Dynamic recrystallization; FE, Finite element; H-P, Hall-Petch; HV, Vickers hardness; SPD, Severe plastic deformation; $T$, Current temperature; $T_{0}$, Reference temperature; $T_{\mathrm{m}}$, Melting temperature; $\dot{\varepsilon}$, Strain rate; $\dot{\varepsilon}_{0}$, Reference strain rate; $\varepsilon$, Effective strain; $\varepsilon_{\text {eff, }}^{\mathrm{p}}$, Effective plastic strain for grain size changes; $\varepsilon^{\mathrm{p}}{ }_{\mathrm{c}}$, Critical plastic strain for grain size changes; $\Phi$, Inner die channel angle; $\Psi$, Outer die channel angle; $d$, Average grain size; $d_{0}$, Initial grain size; $d_{\mathrm{f}}$, Saturation grain size; $k_{y}$, Numerical constant; $k_{X}$, Numerical constant; $\sigma_{\mathrm{y}}$, Yield strength; $\sigma_{0}$, Numerical constant; $m$, Numerical constant; $n$, Numerical constant

\section{Availability of data and materials Not applicable}

Code availability Commercial FE software SFTC DEFORM-3D ${ }^{\mathrm{TM}}$

Author contribution Conceptualization, S.C. and S.I.; methodology, S.C. and S.I.; software, S.C.; validation, S.C.; formal analysis, S.I.; investigation, S.C. and S.I.; resources, S.C. and S.I.; data curation, S.C. and S.I.; writing - original draft preparation, S.C. and S.I.; writing - review and editing, S.C. and S.I.; visualization, S.I.; supervision, S.C. All authors have read and agreed to the published version of the manuscript.
Funding Open access funding provided by Università della Calabria within the CRUI-CARE Agreement.

\section{Declarations}

Ethics approval Not applicable.

Consent to participate Not applicable

Consent for publication Not applicable

Conflict of interest The authors declare no competing interests.

Open Access This article is licensed under a Creative Commons Attribution 4.0 International License, which permits use, sharing, adaptation, distribution and reproduction in any medium or format, as long as you give appropriate credit to the original author(s) and the source, provide a link to the Creative Commons licence, and indicate if changes were made. The images or other third party material in this article are included in the article's Creative Commons licence, unless indicated otherwise in a credit line to the material. If material is not included in the article's Creative Commons licence and your intended use is not permitted by statutory regulation or exceeds the permitted use, you will need to obtain permission directly from the copyright holder. To view a copy of this licence, visit http://creativecommons.org/licenses/by/4.0/.

\section{References}

1. Krishna GV, De TN, Burman RK, Sekhar BV, Rao VG (2019) Numerical and experimental comparative study of Aluminum and hybrid mounting interfaces of launch vehicle avionics for weight reduction. Procedia Struct Integrity 14:820-829. https://doi.org/10. 1016/j.prostr.2019.07.060

2. Palazzo J, Geyer R (2019) Consequential life cycle assessment of automotive material substitution: Replacing steel with aluminum in production of north American vehicles. Environ Impact Assess Rev 75:47-58. https://doi.org/10.1016/j.eiar.2018.12.001

3. Sakai T, Jonas JJ (1984) Overview n.35 Dynamic recrystallization: mechanical and microstructural considerations. Acta Metal 32(2): 189-209. https://doi.org/10.1016/0001-6160(84)90049-X 
4. Busso EP (1998) A continuum theory for dynamic recrystallization with microstructure-related length scales. Int J Plast 14(4-5):319353. https://doi.org/10.1016/S0749-6419(98)00008-4

5. Zhao H, Ren Y, Yang B, Qin G (2019) Microstructural evolution of equal channel angular drawn purity titanium at room temperature. J Alloys Compd 811:152002. https://doi.org/10.1016/j.jallcom.2019. 152002

6. Pu ZW, Caruso S, Umbrello D, Dillon OW, Puleo DA, Jawahir IS (2011) Analysis of surface integrity in dry and cryogenic machining of AZ31B Mg alloys. Adv Mat Res 223:439-448. https://doi.org/ 10.4028/www.scientific.net/AMR.223.439

7. Zhilyaev AP, Swisher DL, Oh-ishi K, Langdon TG, McNelley TR (2006) Microtexture and microstructure evolution during processing of pure aluminum by repetitive ECAP. Mater Sci Eng A 429(12):137-148. https://doi.org/10.1016/j.msea.2006.05.009

8. Suwas S, Arruffat Massion R, Tóth LS, Fundenberger JJ, Beausir B (2009) Evolution of texture during equal channel angular extrusion of commercially pure aluminum: experiments and simulations. Mater Sci Eng A 520(1-2):134-146. https://doi.org/10.1016/j. msea.2009.05.028

9. Faraji G, Torabzadeh H (2019) An overview on the continuous severe plastic deformation methods. Mater Trans 60(7):1316 1330. https://doi.org/10.2320/matertrans.MF201905

10. Suriadi AB, Thomson PF (1997) Control of deformation history for homogenizing and optimizing mechanical properties of metals. Proceedings of Australiasia-Pacific Forum on Intelligent Processing \& Manufacturing of Materials. IPMM:920-926

11. Luis Pérez CJ, Berlanga C, Pérez-Ilzarbe J (2003) Processing of aluminium alloys by equal channel angular drawing at room temperature. J Mater Process Technol 143-144:105-111. https://doi. org/10.1016/S0924-0136(03)00329-7

12. Chakkingal U, Suriadi AB, Thomson PF (1998) Microstructure development during equal channel angular drawing of $\mathrm{Al}$ at room temperature. Scr Mater 39(6):677-684. https://doi.org/10.1016/ S1359-6462(98)00234-6

13. Hou JP, Wang Q, Yang HJ, Wu XM, Li CH, Li XW, Zhang ZF (2015) Microstructure evolution and strengthening mechanisms of cold-drawn commercially pure aluminum wire. Mater Sci Eng A 639:103-106. https://doi.org/10.1016/j.msea.2015.04.102

14. Zisman AA, Rybin VV, Van Boxel S, Seefeldt M, Verlinden B (2006) Equal channel angular drawing of aluminium sheet. Mater
Sci Eng A 427(1-2):123-129. https://doi.org/10.1016/j.msea.2006. 04.007

15. Zhu YK, Chen QY, Wang Q, Yu HY, Li R, Hou JP, Zhang ZJ, Zhang GP, Zhang ZF (2018) Effect of stress profile on microstructure evolution of cold-drawn commercially pure aluminum wire analyzed by finite element simulation. J Mater Sci Technol 34(7): 1214-1221. https://doi.org/10.1016/j.jmst.2017.07.011

16. Chakkingal U, Suriadi AB, Thomson PF (1999) The development of microstructure and the influence of processing route during equal channel angular drawing of pure aluminum. Mater Sci Eng A 266(1-2):241-249. https://doi.org/10.1016/S0921-5093(98)011290

17. Luo XM, Song ZM, Li ML, Wang Q, Zhang GP (2017) Microstructural evolution and service performance of cold-drawn pure aluminum conductor wires. J Mater Sci Technol 33(9):10391043. https://doi.org/10.1016/j.jmst.2016.11.018

18. Hallberg H (2011) Approaches to modeling of recrystallization. Metals 1(1):16-48. https://doi.org/10.3390/met1010016

19. Jonas JJ (1994) Dynamic recrystallization - scientific curiosity or industrial tool? Mater Sci Eng A 184(2):155-165. https://doi.org/ 10.1016/0921-5093(94)91028-6

20. Hallberg H, Wallin M, Ristinmaa M (2010) Modeling of continuous dynamic recrystallization in commercial-purity aluminium. Mater Sci Eng A 527(4-5):1126-1134. https://doi.org/10.1016/j. msea.2009.09.043

21. Sakai T, Miura H, Yang X (2009) Ultrafine grain formation in face centered cubic metals during severe plastic deformation. Mater Sci Eng A 499(1-2):2-6. https://doi.org/10.1016/j.msea.2007.11.098

22. Yamagata H, Ohuchida Y, Saito N, Otsuka M (2001) Nucleation of new grains during discontinuous dynamic recrystallization of 99.998 mass\% Aluminum at 453K. Scr Mater 45(9):1055-1061. https://doi.org/10.1016/S1359-6462(01)01139-3

23. Iwahashi Y, Wang J, Horita Z, Nemoto M, Langdon TG (1996) Principle of equal-channel angular peessing for the processing of ultra-fine grained materials. Scr Mater 35(2):143-146. https://doi. org/10.1016/1359-6462(96)00107-8

Publisher's note Springer Nature remains neutral with regard to jurisdictional claims in published maps and institutional affiliations. 